\title{
Impact of Intra-group Conflict on Group Performance-moderating Role of Cultural Diversity
}

\author{
Faisal Hanif*, Mohsin Khan, Muhammad Adeel, Syed Mehmood Shah \\ Capital University of Science and Technology Islamabad, Pakistan
}

Copyright $(\mathcal{C} 2016$ by authors, all rights reserved. Authors agree that this article remains permanently open access under the terms of the Creative Commons Attribution License 4.0 International License

\begin{abstract}
In the present study, a model was developed to describe relationships between impacts of intra-group conflict on group performance-moderating role of cultural diversity. Data from 170 employees working in teams of GSM cellular companies located in Pakistan support our hypothesis. Data was analyzed through SPSS. Findings indicated that intragroup conflict had direct negative effects on group performance effectiveness. Furthermore, our findings suggest that reducing intragroup conflict and providing team members with the abilities to manage conflict effectively is a way to increase group performance and implement strategies to decrease a stressful work environment and increase team-building activities. At the end, conclusion, limitations, and future research directions are also discussed.
\end{abstract}

Keywords Cognitive Task Conflict, Emotional Conflict, Group Performance, Cultural Diversity

\section{Introduction}

Conflict is normally viewed as difference of interests or ideas [1]. Organizational conflict about disagreement that happens when the goals of different persons or groups are mismatched and affects each other's performance which makes it difficult in achieving their objectives [2]. It is difficult to avoid conflict during the organizational life time; because of different stakeholders outside the organization and within the organization having different goals such as employer and employee are often incompatible.

Conflict is an important aspect of life where individuals compete for jobs, resources, authority, and safety. It is hard to deal with the conflict, because it produces emotions when the individuals feel threatened, thereby creates tension, anxiety inducing the response of anger and fight [3].

Intra-group conflicts raise from either task or relationship issues $[4 ; 5]$. Relationship conflict or emotional conflict described by the personality clashes or negative emotional interaction between two or more people, who are connected with rigidity, dislike, and annoyance. Whereas, task conflict mentions the divergences about content of decisions and different views, thoughts, ideas, key decision areas and procedures, among group members [6].

Based on social information handling theories [7], self-categorization theory [8] many researchers have submitted the findings that groups which are culturally diverse they face more negative outcomes of groups than the groups having cultural similarity just because of preference, bias against members, mistakes in communication, different perceptions, acknowledgements among the members of group [9].

Due to cultural Differences individuals have different beliefs and values, as a result individuals have different approaches to perceptions of conflict, therefore it can be difficult to resolve conflict and also affect the ability of resolution. Moreover, these undesirable features affect the performance of the group that is culturally diverse. It is likely that the cultural diversity will be negatively related to the perceived performance of the group. Performance is recognized as one of the important indicators of the group efficacy [10] and often used as an outcome variable in the literature of intragroup conflict $[11 ; 12]$.

Different researchers have found out that all the three forms of conflict (Relationship, Process, and Task Conflict) have differential influence on effectiveness of a group in relation to performance outcomes. It reduces mutual understanding due to relationship conflict, hence prevents the completion of group tasks [13].

Despite the fact that intragroup conflict in the organizations has seized the attention of researchers many times and also produced substantial research outcomes but still a vast portion of the variance remains unanswered. There is a need to probe other variables, such as cultural diversity, particularly in the context of Pakistan where the change and growth is visible in the service industry. As a result this sector is more diversified in the form of its workforce and investment. This scenario has incited to explore the new working environment in Pakistan, i.e., the interrelationship between behavioral features and 
performance. Aiming at this, one of the most thriving industries of Pakistani service sector is selected for the research i.e. the telecom industry.

So, this empirical study is conducted to find whether and to what extent the Cultural Diversity moderates the relationship between Intragroup Conflict and Group outcomes. This study serve the management to have better understanding of how Intra-group conflicts (Cognitive Task Conflict and Emotional Conflict) affect the group output or performance and how cultural diversity of employees positively or negatively influence the rising Intra-group conflicts.

The findings of this study help the management to cope up with the problems of Intra-group conflicts affecting group outcomes or performance. The study is also aimed at handling conflicts in the organizations and recommending useful means of using conflict to boost the creativeness and group outcomes, thereby making the organization globally competitive.

\section{Literature Review}

Intragroup Conflict

[14] Identified four types of organizational conflicts. First is interpersonal conflict, this type of conflict occurs between individuals when they face interference in their domains of work responsibilities by another person and harming or disrupting their efforts towards achieving their goals and objectives. The second form of conflict is Intra-group conflict which refers to a conflict between two or more members of a same group or team. Third type is Inter-group conflict; this type of conflict occurs between two or more groups or teams. The fourth form of conflict is Inter-organizational conflict that occurs across the organizations.

Intragroup Conflict is a state when group members see disagreements, divergences and mismatched thoughts or ideas amongst them [15]. Intragroup conflict is distinct as it develops from implicit or real mismatches among group members [16]. Earlier empirical studies on intragroup conflicts have mostly stressed on conflicts rising from either task or relationship issues [17]. Conflict of Rapport is described as relational mismatches amongst the group members which are connected with strain, dislike, and frustration.

Task Conflict may refer to the disparities and inconsistencies among group members about the content of their judgments, conclusions and encompasses dissimilarities in perspectives, notions and views, key decision areas and procedures [18]. Different forms of conflict have inconsistent impact on group efficacy in view of behavioral and performance aftermaths [13].

Recent studies have identified another unique kind of conflict, labeled as Process Conflict $[19 ; 20]$. Process Conflict is the consciousness about the disagreements featuring different facets of task accomplishment. Precisely, Process Conflict refers to matters of responsibility; resource allocation like who will do what and to what extent he/she will be held responsible for his/her acts [21].

Literature has supported the fact that conflict may help the decision makers or the management in evaluating the job performance of groups and may induce more commitment and motivation among the group members towards fulfilling the organizational objectives [22].

\section{Cognitive Task Conflict and Group Performance}

Perspective or Cognitive Task Conflict may have diverse influences on group working and group outcomes identified as group performance. Task oriented conflict is more expected to have constructive influence on group working [23]. There is not a perfect association between Task Conflict and Group performance though but many researchers have found that exceedingly high levels of Task Conflict occasionally produce less contentment and obligation among the group members towards team's objectives; hence Task Conflict shares both negative and positive impact on group performance [24].

Task Type was identified as moderator between Task Conflict and Group Performance. Task Conflict was found more valuable to the groups accomplishing non-repetitive tasks and not suitable to the groups doing normal routine tasks. As an outcome, groups with non-defined tasks or performing different tasks are more inclined to get benefited from Task oriented conflict [25].

It is vital to discover the facilitating approach under the circumstances of Task Conflict. Many research findings have recognized the progressive influences of Task Conflict like better decision making and improved productivity and Task Conflicts may augment the task application of members included; like producing or sharing new information, enhanced communication, mutual or shared information and group problem resolving [26].

The conflict researchers have proposed that relationship conflict may activate task conflict as a consequence of an effort by a group member in creating problems for his other group mate [27].

Hypothesis 1: Cognitive Task Conflict will negatively influence the Group Performance.

\section{Emotional Conflict and Group Performance}

The emotional conflict may be relationship oriented [27]. The empirical study on the effects of relationship conflict has mostly reinforced these theoretical research findings. Emotionality is broadly described as a particular sentimental state of mind. The description is incorporating the main feelings like annoyance, happiness, affection, social feelings like disgrace, distrust, guilt as well as concepts like distress, emotions and dispositions.

Feeling and emotionality are the terms which have been used in substitution for each other in the literature [28]. Relationship Conflict is positively related with group 
members' opinions of inequality and negatively related to observed group performance [13]. As a consequence, relationship conflict negatively impact on group performance and also moderates the relationship between task-oriented conflict and group performance [29].

In recent times [6], also highlighted that high level of task conflict could trigger relationship conflict amongst the group members and also debated that the differences among the group members about any task may generate negative sentiments and as a consequence creates relationship conflict.

Hypothesis 2: Emotional Conflict will negatively influence the Group Performance.

\section{Cultural Diversity and Group Performance}

The concept of culture has been defined in many different ways $[30 ; 31]$ that variously emphasize its cognitive, behavioral, symbolic, value-related, linguistic, historical, or geographic characteristics [32]. In an effort to reconcile these different definitions, [33] suggests that the concept of a cultural syndrome may facilitate the understanding of culture and cultural differences.

The notion of culture is described through various diverse means and techniques [13]. Those various means emphasize its intellectual, social, representational, value-related, stated, historic, or geographical features [34]. The main attention of diversity research has been on plugging in the geographical variances amongst the group members such as age, sex, or race on their way towards team level operations like team societal assimilation and productivity [35].

Individualism and Collectivism are the situations or circumstances usually referenced as to differentiate between the cultures [36]. A societal shape related to people's acknowledged individuality from collective farm with their own individual likings, necessities and objectives is referred to Individualism. In divergence, people's professed interdependence with Collectives and the likings, necessities and objectives are mutual with others is termed as Collectivism [37]. There are also basic potentials which are not so simply or hastily judged by others like talents, aptitudes, beliefs, knowledge and behaviors. These characteristics requires more time, interpersonal meetings, communication to be known by others. These fundamental elements are very so often mentioned as imperceptible or very difficult to understand. Divergences in expertise and knowledge are also deliberated as functional diversity [38].

Hypothesis 3: Cultural Diversity will moderate the relationship between Emotional Conflict and the Group Performance.

Hypothesis 4: Cultural Diversity will moderate the relationship between Cognitive Task Conflict and the Group Performance.

\section{Theoretical Framework}

Theoretical framework shows relevant literature and proposed structural model. Group Performance acts as the dependent variable which will possibly depict the influence of independent variable Intra-Group Conflict measured by Cognitive Task Conflict and Emotional Conflict. Task conflict is the disagreement on processes and procedures of performing and the emotional conflict reflects the personality differences, attitudes and different conflicting behaviors arising among different individuals. The Cultural Diversity will act as a moderating variable. Cultural Diversity would influence the relationship positively or negatively between different forms of Intra-group Conflict (Emotional Conflict and Cognitive Task Conflict) and Group Performance.

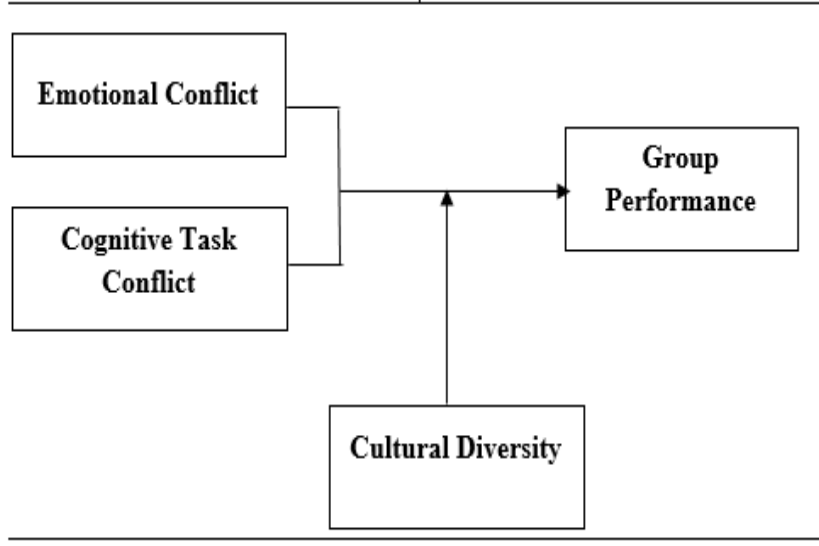

Figure 1. Theoretical Framework

\section{Methods}

\section{Data Collection and Sample}

The sample comprised of employees of all five well established private GSM cellular companies located in Pakistan. Data were gathered through onsite survey in five different GSM cellular companies. The business and operations of the organizations encompassed telecom engineering services, cellular connections and services. The research access to these organizations was made possible by the authors by using their private and professional contacts for the conduct of survey and using these five private companies across Pakistan as sample.

The questionnaires were distributed to the available male and female senior managers, managers, team leads and employees at the junior levels in different organizational units. All of the completed questionnaires were collected by the authors themselves. These questionnaires also had a cover page stating the purpose and scope of the research by ensuring the anonymity of the respondents. A total of three hundred disseminated questionnaires produced one hundred and ninety two (192) at a return rate of 64 percent. After separating incomplete questionnaires one hundred and seventy (170) at an effective response rate of 56 percent were used for analysis.

The educational qualifications of the respondents 
remained between College levels to MS/MPhil level having about 60 percent respondents who obtained formal university education. The mean age of the respondents was thirty (30) years with an average tenure of six (6) years.

\section{Questionnaire/Tool}

28 items questionnaire $[12 ; 39]$, is used to measure the relationship between different forms of Intragroup Conflict and the Group Performance and the influence of Cultural Diversity on this relationship. I measured relationship conflict $(\alpha=0.77)$ and task conflict $(\alpha=0.72)$ with the scales developed by [12]. A sample item for this scale is "how much disagreement among group members is there about how tasks should be accomplished?" perceived performance of the group was measured with [50] eight-item group performance scale that taps into a broad range of performance dimensions, such as meeting schedules and being innovative ( $\alpha=0: 73$ ).

Each form of Intragroup conflict is measured by five different items using 5 -likert scale of $1=$ strongly disagree to $5=$ strongly agree and higher mean values showed high levels of corresponding trait. The statements examples for Emotional Conflict include (Narrow-mindedness or envy usually drives the conflict in our workgroup, When differences occur, some group members tries to put themselves forward at the expense of others, The conflict is also caused by personal clashes in our group, There are tendencies of anger and aggression between some persons in our group, There is a high degree of emotional conflict in our workgroup).

The statements examples for Cognitive Task Conflict include (During the conflict, our group is concerned about solving problems by using a sensible and rational procedure, Our disagreements are tasks oriented and put reasons before emotions, While disagreeing on the subject matter, feelings are kept under control and argued in a logical and analytical manner, Conflict of ideas occur in our work group, There are frequent disagreements within our workgroup about the tasks we are working on).

The statements examples for Group Performance include
(Our group works in cohesion, We have high group spirit, The conflict affects group performance, Our group often fails to perform essential duties, Our group meets all the formal performance requirements of the assigned tasks)

The statements examples for Cultural Diversity include ( Our group members belongs to different regions of Pakistan, Our group members speaks different mother tongues, Our group members are from different ethnicity, Our group members have different educational level, Our group members have variety of abilities, Our group members have different interpersonal skills, Considering all, our group is a culturally diverse group).

The reliability approximations found for Emotional Conflict Cronbach's Alpha 0.77, Cognitive Task Conflict Cronbach's Alpha 0.72, Group Performance Cronbach's Alpha 0.73, and Cultural Diversity Cronbach's Alpha .84

\section{Control Variables}

In current study, gender, age, education and tenure were taken as control variables. Prior research studies show that these demographic variables are predictors of group performance [40].

\section{Correlation analysis}

Table 1 shows the correlation coefficients between different variables of the study. The correlation coefficient ranges between -1 and +1 . A correlation value of above 0.5 depicts a strong positive association between the variables. It is noted that almost all the variables of the study i.e. cognitive task conflict, emotional conflict and cultural diversity have a significant correlation with the dependent variable of group performance $(p<0.05)$. Multiple regression analysis was conducted to see the combined effect of all independent variables over the dependent variable of group performance. The $\mathrm{R}$-square value $(\mathrm{R} 2=0.19)$ shows that $19 \%$ variance in the dependent variable of group performance is explained by the independent variables, emotional conflict and cognitive task conflict.

Table 1. Correlations between measures

\begin{tabular}{|c|c|c|c|c|c|c|}
\hline Variable & Mean & S.D. & GP & EC & CTC & CD \\
\hline GP & 3.6892 & 0.4897 & 1 & & & \\
\hline EC & 3.6766 & 0.5856 & $-.465^{* *}$ & 1 & & \\
\hline CTC & 3.6475 & 0.5896 & $-.372^{* *}$ & $.501^{* *}$ & 1 & \\
\hline CD & 3.6259 & 0.5914 & $.466^{* *}$ & $.391^{* *}$ & $.565^{* *}$ & 1 \\
\hline
\end{tabular}

Note. ${ }^{* *} \mathrm{p}<0.01, \mathrm{~N}=170 \mathrm{GP}=$ group performance, $\mathrm{EC}=$ emotional conflict, $\mathrm{CTC}=$ cognitive task conflict, $\mathrm{CD}=\mathrm{Cultural}$ diversity.

** Correlation is significant at the 0.01 level (2-tailed).

* Correlation is significant at the 0.05 level (2-tailed).

Table 2. Regression statistics

\begin{tabular}{|c|c|c|c|}
\hline Variable & Beta & t-value & p-value \\
\hline Emotional Conflict & -0.072 & -0.598 & 0.011 \\
\hline Cognitive Task Conflict & -0.128 & -1.529 & 0.028 \\
\hline R-square & 0.19 & & \\
\hline
\end{tabular}




\section{Results}

Table 2 shows the beta values and significance values of the independent variables. Emotional Conflict has a significant negative relationship with group performance $(\mathrm{p}$ $<.05 ; \beta=-.072$ ) which means that emotional conflict have significant impact on group performance. Likewise, cognitive task conflict $(\mathrm{p}<.05 ; \beta=-.128)$ also have significant negative impact on group performance as evident from the results of regression analysis.

In order to see whether cultural diversity moderates the relationship between independent variables and the dependent variable of group performance, a moderated regression analysis was carried on. Table 3 shows the results of moderated regression analysis.

Table 3. Moderated Regression Analysis

\begin{tabular}{|c|c|c|c|}
\hline Interaction term & $\mathrm{B}$ & t-value & $\mathrm{p}$-value \\
\hline ECxCD & 1.279 & 2.593 & $0.010^{* *}$ \\
\hline CTCxCD & 1.978 & 3.956 & $0.000^{* *}$ \\
\hline
\end{tabular}

$\mathrm{EC}=$ emotional conflict, $\mathrm{CD}=$ cultural diversity, $\mathrm{CTC}=$ cognitive task conflict, ${ }^{*} \mathrm{p}<.05,{ }^{* *} \mathrm{p}<.01, * * * \mathrm{p}<.001$

Moderated regression analyses show that cultural diversity significantly moderates the relationship between value emotional conflict ( $\mathrm{p}<.05 ; \beta=1.279$ ), cognitive task conflict $(\mathrm{p}<.05 ; \beta=1.978)$ and group performance.

\section{Discussion}

The findings of this study represent a contribution to the literature on intragroup conflict and show that intragroup conflict has negative relationship with group performance, and cultural diversity and also moderate this relationship. The findings of this study, is highly needed in light of the proliferation of culturally diverse groups in organizations.

On the basis of the above analysis support has been found for hypothesis. In a recent meta-analysis of 30 studies conducted between 1994 and 2001, [40] found that relationship conflict was generally negatively correlated with group member satisfaction and group performance.

However, high levels of task conflict can lead to reduced member commitment and performance of the group. Task conflict had a negative impact on the performance of groups working on routine tasks, but a curvilinear effect on the performance of groups working on non-routine tasks [12]. Low and high levels of task conflict are detrimental, but medium levels of task conflict are beneficial, since they promote critical evaluation of issues facing the group. Similarly, [41] found that work teams with moderate levels of task conflict were more innovative than teams with low or high levels of task conflict. The positive relationship between task conflict and group outcomes, however, may not be generalizable. [40] found in their meta-analysis that task conflict is generally negatively correlated with group member satisfaction and group performance.
In most organizational contexts it is impossible, and for various reasons undesirable, to assemble culturally homogeneous groups that are less prone to intragroup conflict and unfavorable group outcomes. Even though cultural learning tends to be a long process establishing explicit expectations among group members and engaging employees in clear psychological contracts [42] that define what group members can expect to receive and give are likely to have a homogenizing effect on the attitudes, beliefs, norms, role definitions, and values of group members. This effect, lead to less conflict and more favorable group outcomes. In addition, cross-cultural training programs [43] that develop cognitive, affective, and behavioral knowledge about cultural differences are likely to be effective means for attenuating the unfavorable impact of cultural diversity on group conflict and group outcomes.

\section{Conclusions}

Conflicts are inevitable among coworkers in work groups. Conflict in all cultures is unavoidable, but every culture has a changed approach of managing it from the other and its own way of dealing with it. Top Management of the companies like Multinational companies understand the importance of multicultural differences when having international alliances, acquisitions or mergers, therefore in recent era conflict management has become more important and vital for the effective functioning of the organizations [44]. Effective conflict management provides opportunities for the members of group to understand each other in a better way and enhance their group performance, interpersonal skills and building rapport [45].

The term Inter-cultural conflict provides group decision-making, which leads to effective decision making, and an organization can gain great benefit of the multicultural experiences and diversified knowledge and skills if it is managed usefully [46]. Evidence from the present study, however, suggests that cultural diversity moderate the relationship between intragroup conflict and group performance.

The findings of this study corroborate the findings from previous research $[11 ; 12 ; 47]$. However, the findings clearly prove research findings that task conflict and emotional conflict has a negative effect $[48 ; 41 ; 49]$ on group performance.

This study is important for policy makers and academic literature. For policy maker it is important in a sense that it will provide a bridge to them to remove negative conflict and maintain a level of conflict up to an extent where conflict play a role to boost up the group performance. While from academic point, of view it is extension in literature. Beside this, the study has certain limitations. As with all studies, the findings of this paper should be considered in light of its limitations. Limitations that warrant discussion are the cross-sectional design of the study, potential common method bias, the generalizability of the findings, and the low sample size. 


\section{REFERENCES}

[1] Adomi, E. E., \& Ozioma Anie, S. (2006). Conflict management in Nigerian university libraries. Library management, 27(8), 520-530.

[2] Karatepe, O. M., \& Tekinkus, M. (2006). The effects of work-family conflict, emotional exhaustion, and intrinsic motivation on job outcomes of front-line employees. International Journal of Bank Marketing, 24(3), 173-193.

[3] Zepeda, S. J. (2006). Cognitive dissonance, supervision, and administrative team conflict. International Journal of Educational Management, 20(3), 224-232.

[4] Amason, A. C. (1996). Distinguishing the effects of functional and dysfunctional conflict on strategic decision making: Resolving a paradox for top management teams. Academy of management journal, 39(1), 123-148.

[5] Pelled, L. H., Eisenhardt, K. M., \& Xin, K. R. (1999). Exploring the black box: An analysis of work group diversity, conflict and performance. Administrative science quarterly, 44(1), 1-28.

[6] Guerra, J. M., Martínez, I., Munduate, L., \& Medina, F. J. (2005). A contingency perspective on the study of the consequences of conflict types: The role of organizational culture. European Journal of Work and Organizational Psychology, 14(2), 157-176.

[7] Crocker, J., Fiske, S. T., \& Taylor, S. E. (1984). Schematic bases of belief change. In Attitudinal judgment (pp. 197-226). Springer New York.

[8] Turner, J. C. (1987). Rediscovering the social group: A self-categorization theory. Oxford: Basil Blackwell.

[9] Canen, A. G., \& Canen, A. (2008). Multicultural Leadership: the costs of its absence in organizational conflict management. International Journal of Conflict Management, 19(1), 4-19.

[10] Gladstein, D. L. (1984). Groups in context: A model of task group effectiveness. Administrative science quarterly, 499-517.

[11] Jehn, K. A. (1994). Enhancing effectiveness: An investigation of advantages and disadvantages of value-based intragroup conflict. International journal of conflict management, 5(3), 223-238.

[12] Jehn, K. A. (1995). A multimethod examination of the benefits and detriments of intragroup conflict. Administrative science quarterly, 256-282.

[13] Vodosek, M. (2007). Intragroup conflict as a mediator between cultural diversity and work group outcomes. International Journal of Conflict Management, 18(4), 345-375.

[14] Tjosvold, D. (2006). Defining conflict and making choices about its management: Lighting the dark side of organizational life. International Journal of Conflict Management, 17(2), 87-95.

[15] Boulding, K. (1963). Conflict and defence. General Theory. $N Y$.
[16] Appelbaum, S. H., Shapiro, B., \& Elbaz, D. (1998). The management of multicultural group conflict. Team Performance Management: An International Journal, 4(5), 211-234.

[17] Amason, A. C. (1996). Distinguishing the effects of functional and dysfunctional conflict on strategic decision making: Resolving a paradox for top management teams. Academy of management journal, 39(1), 123-148.

[18] Pelled, L. H., Eisenhardt, K. M., \& Xin, K. R. (1999). Exploring the black box: An analysis of work group diversity, conflict and performance. Administrative science quarterly, 44(1), 1-28.

[19] Korsgaard, M. A., Ployhart, R. E., \& Ulrich, M. D. (2014). The emergence of intragroup conflict: Variations in conflict configurations. Handbook of Conflict Management Research, 51-65. doi:10.4337/9781781006948.00010

[20] Zeitzoff, T. (2013). Anger, Exposure to Violence, and Intragroup Conflict: A "Lab in the Field" Experiment in Southern Israel. Political Psychology, 35(3), 309-335. doi:10.1111/pops.12065

[21] Jehn, K. A., \& Mannix, E. A. (2001). The dynamic nature of conflict: A longitudinal study of intragroup conflict and group performance. Academy of management journal, 44(2), 238-251.

[22] Correll, J., Park, B., \& Smith, J. A. (2008). Colorblind and multicultural prejudice reduction strategies in high-conflict situations. Group Processes \& Intergroup Relations, 11(4), 471-491.

[23] Chuang, Y. T., Church, R., \& Zikic, J. (2004). Organizational culture, group diversity and intra-group conflict. Team Performance Management: An International Journal, $10(1 / 2), 26-34$.

[24] DeChurch, L. A., Hamilton, K. L., \& Haas, C. (2007). Effects of conflict management strategies on perceptions of intragroup conflict. Group Dynamics: Theory, Research, and Practice, 11(1), 66.

[25] Amason, A. C. (1996). Distinguishing the effects of functional and dysfunctional conflict on strategic decision making: Resolving a paradox for top management teams. Academy of management journal, 39(1), 123-148.

[26] Rispens, S. (2009). Do fights prohibit helping? The influence of task interdependence and conflict norms on helping behavior during task conflict. International Journal of Conflict Management, 20(2), 158-172.

[27] Simons, T. L., \& Peterson, R. S. (2000). Task conflict and relationship conflict in top management teams: the pivotal role of intragroup trust. Journal of applied psychology, 85(1), 102 .

[28] Nair, N. (2008). Towards understanding the role of emotions in conflict: a review and future directions. International Journal of Conflict Management, 19(4), 359-381.

[29] Hjertø, K. B., \& Kuvaas, B. (2009). Development and empirical exploration of an extended model of intra-group conflict. International Journal of Conflict Management, 20(1), 4-30.

[30] Bond, M. H., \& Smith, P. B. (1996). Cross-cultural social and organizational psychology. Annual review of psychology, 
$47(1), 205-235$.

[31] Kroeber, A. L., \& Kluckhohn, C. (1952). Culture: A critical review of concepts and definitions. Papers. Peabody Museum of Archaeology \& Ethnology, Harvard University.

[32] Triandis, H. C. (1996). The psychological measurement of cultural syndromes. American Psychologist, 51(4), 407.

[33] Triandis, H. C. (1995). Individualism \& collectivism. Westview press.

[34] Jehn, K. A., Northcraft, G. B., \& Neale, M. A. (1999). Why differences make a difference: A field study of diversity, conflict and performance in workgroups. Administrative science quarterly, 44(4), 741-763.

[35] Harrison, D. A., Price, K. H., Gavin, J. H., \& Florey, A. T. (2002). Time, teams, and task performance: Changing effects of surface-and deep-level diversity on group functioning. Academy of management journal, 45(5), 1029-1045.

[36] Hofstede, G. (1980). Motivation, leadership, and organization: do American theories apply abroad? Organizational dynamics, 9(1), 42-63.

[37] Hofstede, G. (2011). Dimensionalizing cultures: The Hofstede model in context. Online readings in psychology and culture, 2(1), 8 .

[38] Williams, K. Y., \& O'Reilly, C. A. (1998). Demography and diversity in organizations: A review of 40 years of research. Research in organizational behavior, 20, 77-140.

[39] Jehn, K. A., \& Mannix, E. A. (2001). The dynamic nature of conflict: A longitudinal study of intragroup conflict and group performance. Academy of management journal, 44(2), 238-251.

[40] De Dreu, C. K., \& Weingart, L. R. (2003). Task versus relationship conflict, team performance, and team member satisfaction: a meta-analysis. Journal of applied Psychology, $88(4), 741$.
[41] De Dreu, C. K. (2006). When too little or too much hurts: Evidence for a curvilinear relationship between task conflict and innovation in teams. Journal of Management, 32(1), 83-107.

[42] Rousseau, D. (1995). Psychological contracts in organizations: Understanding written and unwritten agreements. Sage.

[43] Black, J. S., \& Mendenhall, M. (1990). Cross-cultural training effectiveness: A review and a theoretical framework for future research. Academy of management review, 15(1), 113-136.

[44] Kim, T. Y., Wang, C., Kondo, M., \& Kim, T. H. (2007). Conflict management styles: the differences among the Chinese, Japanese, and Koreans. International journal of conflict management, 18(1), 23-41.

[45] Park, H. S., Park, C. Y., Oh, S. W., \& Yoo, H. J. (2008). Prevalence of obesity and metabolic syndrome in Korean adults. obesity reviews, 9(2), 104-107.

[46] Boonsathorn, W. (2007). Understanding conflict management styles of Thais and Americans in multinational corporations in Thailand. International Journal of Conflict Management, 18(3), 196-221.

[47] Jehn, K. A. (1997). A qualitative analysis of conflict types and dimensions in organizational groups. Administrative science quarterly, 530-557.

[48] Amason, A. C., \& Schweiger, D. M. (1994). Resolving the paradox of conflict, strategic decision making, and organizational performance. International Journal of Conflict Management, 5(3), 239-253.

[49] Tjosvold, D. (1991). The conflict-positive organization: Stimulate diversity and create unity (Vol. 51485). Addison-Wesley.

[50] Ancona, D.G. and Caldwell, D.F. (1992b), "Demography and design: predictors of new product team performance", Organization Science, Vol. 3 No. 3, pp. 321-41. 